Article

\title{
Determination of Trace Levels of Nickel(II) by Adsorptive Stripping Voltammetry Using a Disposable and Low-Cost Carbon Screen-Printed Electrode
}

\author{
Víctor Padilla ${ }^{1}$, Núria Serrano ${ }^{1,2, *(\mathbb{D})}$ and José Manuel Díaz-Cruz ${ }^{1,2, *(\mathbb{D})}$ \\ 1 Department of Chemical Engineering and Analytical Chemistry, University of Barcelona, \\ Martí i Franquès 1-11, 08028 Barcelona, Spain; victorpadilla777@gmail.com \\ 2 Institut de Recerca de l'Aigua (IdRA), University of Barcelona, 08028 Barcelona, Spain \\ * Correspondence: nuria.serrano@ub.edu (N.S.); josemanuel.diaz@ub.edu (J.M.D.-C.)
}

check for

updates

Citation: Padilla, V.; Serrano, N.; Díaz-Cruz, J.M. Determination of Trace Levels of Nickel(II) by

Adsorptive Stripping Voltammetry Using a Disposable and Low-Cost Carbon Screen-Printed Electrode. Chemosensors 2021, 9, 94. https:// doi.org/10.3390/chemosensors9050094

Academic Editors: Edelmira Valero and Nicole Jaffrezic-Renault

Received: 15 March 2021

Accepted: 23 April 2021

Published: 26 April 2021

Publisher's Note: MDPI stays neutral with regard to jurisdictional claims in published maps and institutional affiliations.

Copyright: (c) 2021 by the authors. Licensee MDPI, Basel, Switzerland. This article is an open access article distributed under the terms and conditions of the Creative Commons Attribution (CC BY) license (https:/ / creativecommons.org/licenses/by/ $4.0 /)$.

\begin{abstract}
A commercial and disposable screen-printed carbon electrode (SPCE) has been proposed for a fast, simple and low-cost determination of $\mathrm{Ni}$ (II) at very low concentration levels by differential pulse adsorptive stripping voltammetry (DPAdSV) in the presence of dimethylglyoxime (DMG) as complexing agent. In contrast with previously proposed methods, the Ni(II)-DMG complex adsorbs directly on the screen-printed carbon surface, with no need of mercury, bismuth or antimony coatings. Well-defined stripping peaks and a linear dependence of the peak area on the concentration of $\mathrm{Ni}(\mathrm{II})$ was achieved in the range from 1.7 to $150 \mu \mathrm{g} \mathrm{L}-1$, with a limit of detection of $0.5 \mu \mathrm{g} \mathrm{L}{ }^{-1}$ using a deposition time of $120 \mathrm{~s}$. An excellent reproducibility and repeatability with $0.3 \%(n=3)$ and $1.5 \%$ $(n=15)$ relative standard deviation, respectively, were obtained. In addition, the suitability of the SPCE as sensing unit has been successfully assessed in a wastewater certificated reference material with remarkable trueness and very good reproducibility.
\end{abstract}

Keywords: nickel; dimethylglyoxime; adsorptive stripping voltammetry; carbon screen-printed electrode; water samples

\section{Introduction}

Stripping voltametric methods are especially suitable for trace metal analysis in environmental samples, due to their exceptional features such as good detection limits, reproducibility and selectivity [1]. It is well known that the performance of a voltametric method is closely linked to the material of the working electrode. Trace metal ions determination was traditionally associated with the use of mercury-based electrodes, due to both their high reproducibility and their wide cathodic window [2]. However, the toxicity and the poor versatility as sensing devices of mercury electrodes have been argued as relevant drawbacks; as a result, in the last few years, their use has been progressively decreasing.

Accordingly, in the last two decades, the number of works devoted to the development of sensors with similar electrochemical performance than that exhibited by mercury electrodes has increased rapidly. In addition to the essential requirement of being less toxic, the new electrodes had to be more versatile as sensors than mercury and with a large quantity of supports and modifiers available [3-5]. In this sense, the boom of the screen-printed electrodes (SPEs) as a versatile and low-cost option to traditional solid electrodes has contributed in a very positive way to the development of sensors that are able to work either submerged into a solution, in a unique drop or coupled to a flow system. SPEs can be used either in its bare form or as a support for a large variety of modifications. In addition, their disposability, low-cost and reproducible character allow the substitution of every device after some measurements by a new unit with comparable performance, thus avoiding the periodic and tedious polishing and cleaning protocols of traditional solid electrodes. In this way, taking advantage of the above-mentioned specific features, sensors based on SPEs are very appropriate for continuous monitoring, sample screening and on-site analysis [6-8]. 
On the other hand, it is well reported the potential effects that heavy metals may cause on both human health and environment. Heavy metals enter the surroundings by natural ways and through anthropogenic activities. Indeed, it should be noted that heavy metals are closely linked to water since they can be easily collected in surface or groundwater. While it is true that some of these metals may remain in the water, it is also known that some others can come out and gather on accessible surfaces like plants. Therefore, heavy metals can enter the body via food or drinking water, being particularly hazardous because they tend to bioaccumulate. The build-up of heavy metals can produce malfunctions in the kidneys, liver, the circulatory system and the movement of nerve signals. Some heavy metals may be also involved in the development of several cancers $[9,10]$.

Heavy metals most frequently found in wastewater include arsenic, nickel, chromium, cadmium, copper, lead and zinc, representing all of them an important risk for human health and natural ecosystems [11]. Particularly, nickel is a frequent industrial pollutant that can be found in wastewater around industrial parks with concentrations at times achieving the low millimolar range [12]. Nickel is usually found in the $\mathrm{Ni}(0)$ or $\mathrm{Ni}(\mathrm{II})$ state because of the stability of these species in water [13]. Various sources of $\mathrm{Ni}$ (II) include industry, electroplating, tobacco, primarily refining and welding since nickel is frequently used to produce industrial machines components, electronics, jewellery, stainless steel kitchen utensils, dental or orthopedic implants, coins and magnets. High levels of nickel can also be found in spinach, legumes, nuts and lettuce, as well as in cocoa powder and baking powder [14]. Nuts and cocoa may have nickel levels as high as 3 and 10 ppm, respectively. In a market basket survey completed in the United States, the highest average levels of nickel in $\mu \mathrm{g} / 100 \mathrm{~g}$ were found in nuts (128.2), legumes (55), sweeteners (31.6), grains and grain products (26.2) and mixed dishes and soups (25.3) [15]. Nickel is a potential immunotoxic and immunomodulatory agent apart from its action as an allergen in humans. Moreover, nickel toxicity to humans has obtained serious attention due to its carcinogenic action [16-18]. In this regard, the United States Environmental Protection Agency (EPA) recommends that the nickel levels in drinking water do not exceed $0.1 \mathrm{mg} \mathrm{L}^{-1}$. In view of the statements above, it is critical to develop suitable methods that make possible the on-site determination and monitoring of nickel at low concentrations.

The voltametric determination of $\mathrm{Ni}(\mathrm{II})$ at the very low concentrations found in natural water samples involves the use of preconcentration methods. In the years dominated by mercury electrodes, it was clear that, unlike $\mathrm{Pb}$ (II)- or $\mathrm{Cd}$ (II)-ions, the preconcentration of $\mathrm{Ni}$ (II) could not be done by anodic stripping voltammetry (ASV) since reduced Ni atoms are poorly soluble in mercury. A solution to this problem was found with a "classical" method of adsorptive stripping voltammetry (AdSV) with dimethylglyoxime (DMG) [19,20]. In this method, $\mathrm{Ni}(\mathrm{II})$ is complexed by DMG in solution and the resulting $\mathrm{Ni}(\mathrm{DMG})_{2}$ complex adsorbs and accumulates onto the surface of the mercury electrode, where $\mathrm{Ni}$ (II) can be further reduced by means of a cathodic scan. In this way, an enhanced reduction signal is obtained. When mercury electrodes started to become obsolete, alternative approaches were required with new electrode materials. In this regard, two basic strategies are found in the literature: (i) using AdSV with DMG again but replacing the mercury surface with bismuth or antimony coatings which can reasonably reproduce its most relevant characteristics [21-34]; and (ii) using stripping techniques with modified electrodes based on DMG which incorporate the ligand to the electrode and not to the solution [35-42]. In both cases, either the classical glassy carbon electrodes or the screen-printed electrodes were used as a support for the corresponding modifications.

Thus, to the best of our knowledge, on the search for an alternative to mercury, the determination of $\mathrm{Ni}$ (II) has mainly been studied using modified electrodes, neglecting the possibilities of bare electrodes. While it is true that conventional solid electrodes, usually based on carbon (carbon paste or glassy carbon), but also based on gold, silver or platinum, are less toxic and more versatile as sensing units than mercury-based electrodes, they have the disadvantage of having a lower reproducibility and need to be properly cleaned and polished before each determination. However, most of the drawbacks of non-modified 
solid electrodes can be overcome using SPEs as sensing devices because of their abovementioned specific characteristics. Moreover, today, many disposable SPEs from different materials are available on the market at very affordable prices. There is no doubt that the possibility of using an electrode that does not require any modification procedure before being used would certainly simplify and make faster the determination of $\mathrm{Ni}(\mathrm{II})$, since the stage related to the preparation of the electrode, which in some cases is quite laborious and time consuming, would be completely avoided.

Hence, in this work, screen-printed carbon electrode (SPCE) and screen-printed gold electrode (SPAuE) have been selected as two of the most economical, simple, reproducible and popular commercial screen-printed electrodes, and have been applied to the determination of $\mathrm{Ni}(\mathrm{II})$ at trace levels by AdSV using DMG as complexing agent. While SPAuE has not proved to be a valid sensor for the determination of $\mathrm{Ni}(\mathrm{II})$, excellent preliminary results were achieved with SPCE. Thus, SPCE was analytically characterized and applied for the determination of $\mathrm{Ni}(\mathrm{II})$ in a certified wastewater sample, as an example of its suitability for a fast, simple and low-cost analysis of $\mathrm{Ni}(\mathrm{II})$ in samples of environmental interest.

\section{Materials and Methods}

\subsection{Chemicals}

All chemicals were of analytical grade. Stock standard solutions of $\mathrm{Ni}(\mathrm{II})$ at $10 \mathrm{mg} \mathrm{L}^{-1}$, $1 \mathrm{mg} \mathrm{L}^{-1}$ and $100 \mu \mathrm{g} \mathrm{L}^{-1}$ were prepared in ultrapure water from $1000 \mathrm{mg} \mathrm{L}^{-1}$ atomic absorption standard purchased from Alfa Aesar (Ward Hill, MA, USA). Atomic absorption standard solutions of Fe(III), Pd(II), Pt(II) and Co(II), $1000 \mathrm{mg} \mathrm{L}^{-1}$, were supplied by Merck (Darmstadt, Germany).

A $0.1 \mathrm{~mol} \mathrm{~L}^{-1}$ stock solution of dimethylglyoxime (DMG) was prepared in ethanol $96 \%$ and $0.1 \mathrm{~mol} \mathrm{~L}^{-1}$ ammonia/ammonium solution at $\mathrm{pH} 9.2$ served as a buffer.

Wastewater certificated reference material (SPS-WW2) was purchased from Spectrapure Standards (Manglerud, Norway).

The water used through the experiments was purified via Milli-Q plus 185 system (Millipore, Burlington, MA, USA).

\subsection{Apparatus}

For differential pulse adsorptive stripping voltammetric (DPAdSV) measurements an Autolab System PGSTAT12 (EcoChemie, Utrecht, The Netherlands) connected to a VA Stand 663 (Metrohm, Herisau, Switzerland) was used. GPES software version 4.9 (EcoChemie) was employed for data acquisition.

A carbon screen-printed electrode (SPCE, ref. 110) or a gold screen-printed electrode (SPAuE, ref. 220AT) purchased from Metrohm DropSens (Oviedo, Spain) were served as working electrode ( $4 \mathrm{~mm}$ diameter), which was attached by means of a flexible cable (ref. CAC, Metrohm DropSens) to the Autolab System. These electrodes were used as acquired since no previous treatment is needed. $\mathrm{Ag} / \mathrm{AgCl} / \mathrm{KCl}\left(3 \mathrm{~mol} \mathrm{~L}^{-1}\right)$, to which all potentials are referred, supplied by Metrohm (Switzerland) was employed as a reference electrode and as auxiliary electrode it was used the one included in the screen-printed unit. Considering that a reasonable volume of sample was analyzed, the included reference electrode was not used to ensure a better accuracy and for a longer durability of the devices.

For $\mathrm{pH}$ measurements a Crison micro $\mathrm{pH} 2000$ was employed.

\subsection{Voltammetric Measurements}

$\mathrm{Ni}$ (II) calibration curves at SPCE were performed by means of AdSV by adding small volumes of the $\mathrm{Ni}(\mathrm{II})$ stock standard solutions into the electrochemical cell containing $20 \mathrm{~mL}$ of $0.1 \mathrm{~mol} \mathrm{~L}^{-1}$ ammonia/ammonium buffer solution at $\mathrm{pH} 9.2$ and $5 \times 10^{-5} \mathrm{~mol}$ $\mathrm{L}^{-1}$ DMG. AdSV measurements were carried out by applying a deposition potential $\left(\mathrm{E}_{\mathrm{d}}\right)$ of $-0.7 \mathrm{~V}$ during a deposition time $\left(\mathrm{t}_{\mathrm{d}}\right)$ of $120 \mathrm{~s}$ with stirring and after a rest period $\left(\mathrm{t}_{\mathrm{r}}\right)$ of $5 \mathrm{~s}$ without stirringthe AdSV curves were recorded in the potential range from -0.7 to 
$-1.3 \mathrm{~V}$. A pulse times of $50 \mathrm{~ms}$, a pulse amplitude of $100 \mathrm{mV}$ and a step potential of $5 \mathrm{mV}$ were used.

The analysis of the certified wastewater sample using a SCPE was performed by the standard addition calibration method. The AdSV measurements started by putting in the cell a volume of the wastewater sample in $0.1 \mathrm{~mol} \mathrm{~L}^{-1}$ ammonia/ammonium buffer solution (dilution factor 1:500) at $\mathrm{pH} 9.2$ and $5 \times 10^{-5} \mathrm{~mol} \mathrm{~L}^{-1}$ DMG and the voltammogram was recorded. Then, five aliquots of $\mathrm{Ni}$ (II) stock standard solution were added and the respective AdSV curves were recorded.

Three scans are made for each new unit in buffer solution before taking reliable measurements to equilibrate de SPEs. Moreover, for the purpose of ensuring the elimination of the remaining bound $\mathrm{Ni}(\mathrm{II})-\mathrm{DMG}$ complex from the working SPCE surface, in both $\mathrm{Ni}$ (II) calibration curves and analysis of the certified wastewater sample, a conditioning potential $\left(\mathrm{E}_{\text {cond }}\right)$ of $-1.3 \mathrm{~V}$ for $30 \mathrm{~s}$ was applied before each measurement. All experiments were carried out without any oxygen elimination and at room temperature $\left(20^{\circ} \mathrm{C}\right)$.

\section{Results and Discussion}

\subsection{Differential Pulse Adsorptive Stripping Voltammetry of Ni(II)}

Looking for the best analytical response of both SPCE and SPAuE in connection with $\mathrm{Ni}(\mathrm{II})$ determination, two key electrochemical parameters such as the deposition potential $\left(\mathrm{E}_{\mathrm{d}}\right)$ and the deposition time $\left(\mathrm{t}_{\mathrm{d}}\right)$ were initially assessed by AdSV.

DPAdSV measurements of a solution containing $10 \mu \mathrm{g} \mathrm{L}^{-1} \mathrm{Ni}(\mathrm{II})$ at $\mathrm{pH} 9.2$ and $5 \times 10^{-5} \mathrm{~mol} \mathrm{~L}^{-1}$ DMG were done at several $\mathrm{E}_{\mathrm{d}}$ and $\mathrm{t}_{\mathrm{d}}$ values varying from $-0.6 \mathrm{~V}$ to $-1.0 \mathrm{~V}$ and from $30 \mathrm{~s}$ to $240 \mathrm{~s}$, respectively, searching for a compromise between both the analytical response and the time of analysis. A well-defined $\mathrm{Ni}(\mathrm{II})$ peak close to $-1.1 \mathrm{~V}$ that proportionally increased with $t_{d}$ until $120 \mathrm{~s}$ was obtained using a SPCE (Figure S1). For longer $t_{d}$ a diminution of peak area was progressively observed. Therefore, the highest analytical response was achieved applying a $E_{d}$ of $-0.7 \mathrm{~V}$ and a $t_{d}$ of $120 \mathrm{~s}$ as a good agreement between the analytical response and the analysis time. However, when a SPAuE was used, the characteristic $\mathrm{Ni}(\mathrm{II})$ peak was not observed either in any of the $\mathrm{E}_{\mathrm{d}}$ values tested or $t_{d}$ applied. Instead, a background signal was found whose current dramatically increased as the potential was getting more negative (Figure 1), surely due to the $\mathrm{H}_{2}$ discharge. Indeed, gas bubbles were detected on the electrode surface at the most negative potentials. In view of these results, the use of a SPAuE was discarded as a sensing unit for the DPAdSV determination of $\mathrm{Ni}(\mathrm{II})$ and, from here on out, SPCE was used.

After selecting the optimal electrochemical conditions, the repeatability and reproducibility of the SPCE were evaluated. Table 1 summarizes the reproducibility and repeatability values found for the determination of $\mathrm{Ni}(\mathrm{II})$ on SPCE. Repeatability was computed using the same SPCE device for five and fifteen repetitive DPAdSV measurements, respectively, performed in a solution containing $20 \mu \mathrm{g} \mathrm{L} \mathrm{L}^{-1}$ of $\mathrm{Ni}$ (II) in ammonia/ammonium buffer solution at $\mathrm{pH} 9.2$ and $5 \times 10^{-5} \mathrm{~mol} \mathrm{~L}^{-1}$ DMG following the above-established conditions. A highly stable response along 15 consecutive measurements with a relative standard deviation (RSD) of $1.5 \%$ was obtained, proving the excellent response repeatability of SPCE. Reproducibility was calculated from the slope corresponding to the linear range of three independent calibration curves carried out from 0.5 to $150 \mu \mathrm{g} \mathrm{L}^{-1}$ using three different SPCE units. The reproducibility among SPCE units was also outstanding, with RSD values of $0.3 \%$. These repeatability and reproducibility values are better than those achieved for ex-situ antimony film screen-printed carbon electrode and ex-situ bismuth film screen-printed carbon electrode associated to the Ni(II) voltametric stripping peak [34]. 


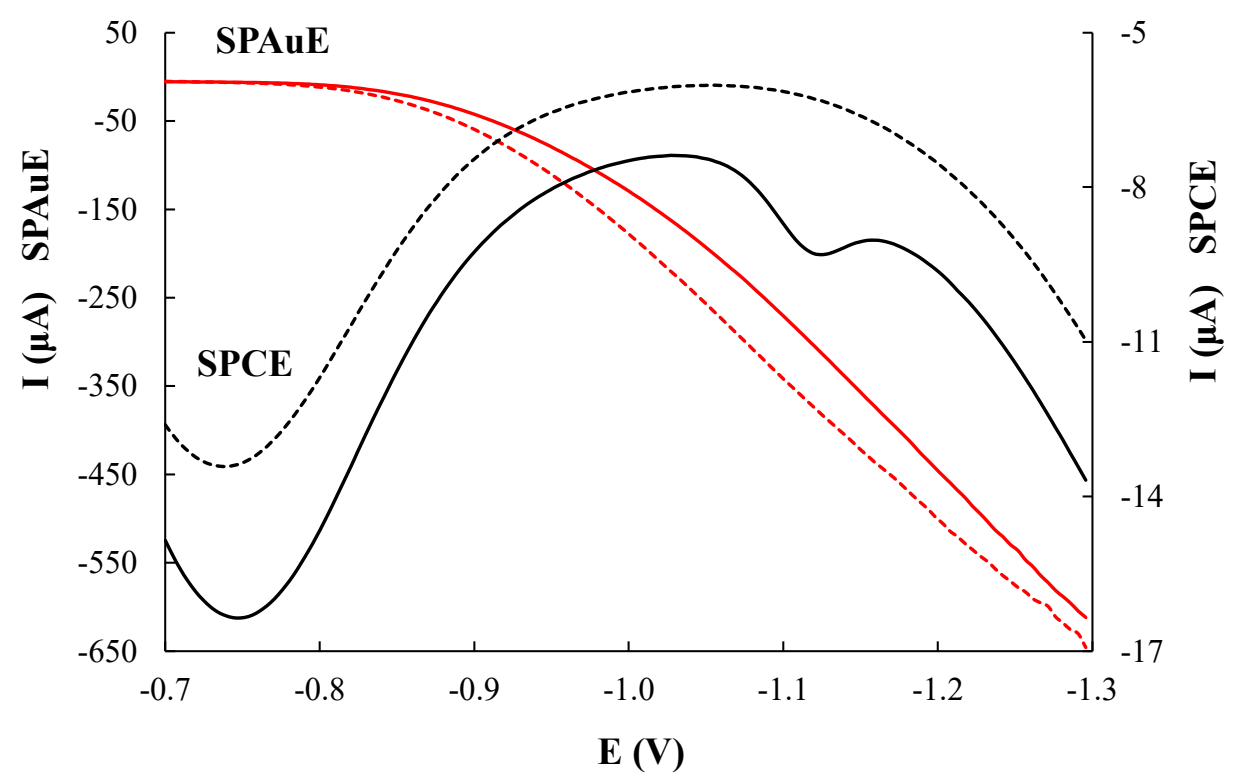

Figure 1. Differential pulse adsorptive stripping voltammograms of $10 \mu \mathrm{g} \mathrm{L}^{-1} \mathrm{Ni}$ (II) recorded on carbon screen-printed electrode, SPCE, (black lines) and gold screen-printed electrode, SPAuE, (red lines) in $0.1 \mathrm{~mol} \mathrm{~L}^{-1}$ ammonia/ammonium buffer solution ( $\mathrm{pH}$ 9.2) and $5 \times 10^{-5} \mathrm{~mol} \mathrm{~L}^{-1} \mathrm{DMG}$ applying a $\mathrm{E}_{\mathrm{d}}$ of $-0.7 \mathrm{~V}$ and $\mathrm{t}_{\mathrm{d}}$ of $120 \mathrm{~s}$. Blank signals in dashed lines.

Table 1. Calibration data for the Ni(II) determination on SPCE at ammonium/ammonia buffer $\mathrm{pH}$ 9.2 applying an $\mathrm{E}_{\mathrm{d}}$ of $-0.7 \mathrm{~V}$ and $\mathrm{a} \mathrm{t}_{\mathrm{d}}$ of $120 \mathrm{~s}$. Standard deviations are denoted by parenthesis.

\begin{tabular}{cc}
\hline Sensitivity (a.u. $\left.\mu \mathbf{g}^{-\mathbf{1}} \mathbf{L}\right)$ & $\mathbf{1 . 0 0 7}(\mathbf{0 . 0 0 2})$ \\
\hline $\mathrm{R}^{2}$ & 0.9998 \\
Linear range $\left(\mu \mathrm{g} \mathrm{L}^{-1}\right.$ ) ${ }^{a}$ & $1.7-150$ \\
LOD $\left(\mu \mathrm{g} \mathrm{L}^{-1}\right)$ & 0.5 \\
Reproducibility (from slopes, $n=3, \%)$ & 0.3 \\
Repeatability (at $\left.20 \mu \mathrm{g} \mathrm{L}^{-1}, n=5, \%\right)$ & 0.4 \\
Repeatability (at $\left.20 \mu \mathrm{g} \mathrm{L}^{-1}, n=15, \%\right)$ & 1.5 \\
\hline
\end{tabular}

${ }^{a}$ LOQ was considered as the lowest value of the linear range.

The analytical performance evaluation was conducted by means of DPAdSV calibration of $\mathrm{Ni}(\mathrm{II})$ metal ion performed in triplicate (a new SPCE unit was used in each replicate). Linear calibration curves were carried out at the optimized conditions by analyzing thirteen $\mathrm{Ni}$ (II) concentrations increasing from 0.5 to $150 \mu \mathrm{g} \mathrm{L}^{-1}$. As it can be seen in Figure 2a, a well-shaped $\mathrm{Ni}(\mathrm{II})$ voltametric stripping peak close to $-1.1 \mathrm{~V}$ that increases with the $\mathrm{Ni}$ (II) concentration was obtained. As shown in Table 1 and Figure $2 \mathbf{b}$, good linear responses of peak area vs. $\mathrm{Ni}(\mathrm{II})$ concentration was attained.

On the other hand, sensitivity was established from the slope of the calibration curve and the limit of detection (LOD) and the limit of quantification (LOQ) were computed as three and ten times, respectively, the standard deviation of the intercept over the slope of the calibration curves. Table 1 reports the calibration data obtained using a SPCE. LOD and LOQ were at the level of $\mu \mathrm{g} \mathrm{L}^{-1}$ and a linear response up to $150 \mu \mathrm{g} \mathrm{L}{ }^{-1}$ was achieved.

Typical concentrations of nickel in sediments and soils range from 4 to $80 \mathrm{mg} \mathrm{Kg}^{-1}$, nickel concentrations in surface water and groundwater range between 3 and $10 \mu \mathrm{g} \mathrm{L}{ }^{-1}$ and in drinking water the average concentration of nickel is between 2 and $4.3 \mu \mathrm{g} \mathrm{L}^{-1}$ [15]. Moreover, as it is stated in the introduction section, the EPA recommends that the nickel levels in drinking water do not exceed $0.1 \mathrm{mg} \mathrm{L}^{-1}$. Therefore, the reported calibration data suggest that SPCE could be a fully appropriate sensor for the determination of $\mathrm{Ni}(\mathrm{II})$ at trace levels in environmental samples. 
(b)

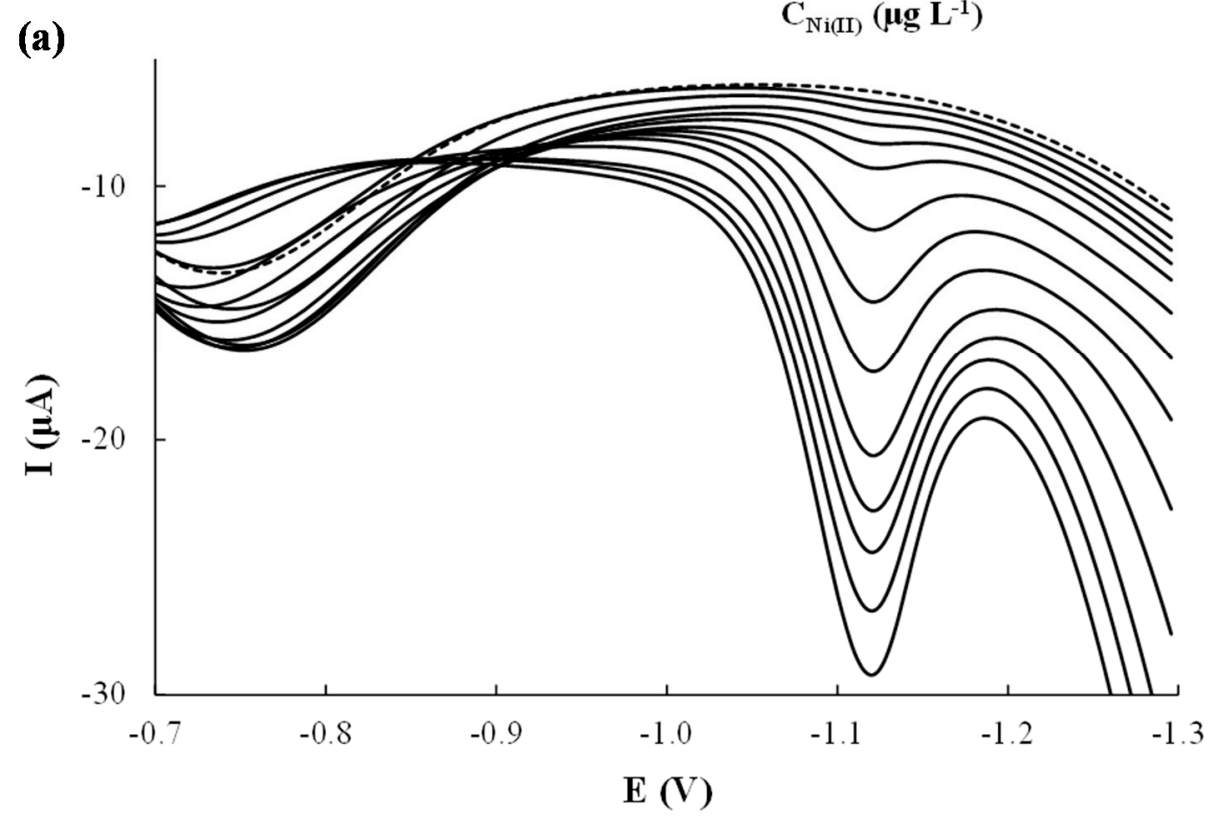

Figure 2. (a) Adsorptive voltammograms and (b) calibration plots of $\mathrm{Ni}$ (II) using a SPCE in $0.1 \mathrm{~mol} \mathrm{~L}^{-1}$ ammonia/ammonium buffer solution ( $\mathrm{pH}$ 9.2) and $5 \times 10^{-5} \mathrm{~mol} \mathrm{~L}^{-1}$ dimethylglyoxime (DMG) applying a $E_{d}$ of $-0.7 \mathrm{~V}$ and $a t_{d}$ of $120 \mathrm{~s}$. Blank signal in dashed line. In (b) error bars of the peak areas are shown.

Regarding previous results connected with the voltametric determination of $\mathrm{Ni}(\mathrm{II})$ and, as can be extracted from Table 2, it should be highlighted that (i) the linear range obtained using a SPCE is much wider and less restricted to lower concentrations than most of the values obtained using bismuth-based, antimony-based, lead-based or mercurybased electrodes; (ii) the obtained LODs and LOQs are considerably lower than most of those provided by modified electrodes based on DMG. Compared to those reported using bismuth-based, antimony-based and lead-based electrodes, the LOD and LOQ obtained using a SPCE are of the order or even slightly better depending on the considered electrode. However, slightly lower LODs were reported when a mercury based- electrode was used as sensing unit; and (iii) the deposition time (120 s) applied using a SPCE is in the lower range of the deposition times reported for the voltametric determination of $\mathrm{Ni}(\mathrm{II})$, which range from 30 to $1500 \mathrm{~s}$, depending on the considered electrode. Therefore, the good analytical performance, together with the fact that SPCEs are non-toxic, low-cost and reproducible devices that do not require any polishing, cleaning or modification procedure, allows us to assert that SPCE can be applied for a fast, simple and low-cost stripping voltametric determination of $\mathrm{Ni}(\mathrm{II})$ at very low concentration levels. 
Table 2. Summary of voltametric methods published so far for the determination of nickel.

\begin{tabular}{|c|c|c|c|c|c|}
\hline Electrode & Technique & $\begin{array}{l}\text { Linear Range } \\
\left(\mu \mathrm{g} \mathrm{L}^{-1}\right)\end{array}$ & $\underset{\left(\mu g L^{-1}\right)}{\operatorname{LOD}}$ & $\begin{array}{l}\text { Deposition } \\
\text { Time (s) }\end{array}$ & Ref. \\
\hline Bismuth film glassy carbon electrode & AdSV & $0-80$ & 0.8 & 180 & [23] \\
\hline Bismuth film glassy carbon electrode & $\begin{array}{c}\text { AdSV } \\
\text { CCAdSCP }\end{array}$ & $2-12$ & 0.26 & 60 & [24] \\
\hline Rotating-disc bismuth-film electrode & SWAdSV & $1-14$ & 0.1 & 300 & [25] \\
\hline Exsitu bismuth film microelectrode & SWAdCSV & $0.2-2$ & 0.09 & 120 & [26] \\
\hline Sputtered bismuth film electrode & SWAdSV & $5-40$ & 0.1 & 90 & [27] \\
\hline Sputtered antimony film electrodes & SWAdSV & $0-30$ & 0.2 & 60 & [28] \\
\hline In-situ bismuth film glassy carbon electrode & SWAdSV & $0.3-3$ & 0.06 & 120 & [29] \\
\hline In-situ antimony film glassy carbon electrode & SWAdSV & $2-20$ & 0.11 & 60 & [30] \\
\hline Solid bismuth vibrating electrode & SWAdCSV & $0-10$ & 0.6 & 30 & {$[31]$} \\
\hline $\begin{array}{l}\text { Macroporous bismuth film screen-printed } \\
\text { carbon electrode }\end{array}$ & AdCSV & $1-10$ & 0.027 & 180 & [32] \\
\hline $\begin{array}{l}\text { Renewable bismuth bulk annular band } \\
\text { working electrode }\end{array}$ & DPAdSV & $0.6-41$ & 0.18 & 30 & [33] \\
\hline $\begin{array}{l}\text { Ex-situ antimony film screen-printed } \\
\text { carbon electrode }\end{array}$ & \multirow[b]{2}{*}{ DPAdSV } & 3.1-197 & 0.9 & \multirow{3}{*}{120} & \multirow{3}{*}{ [34] } \\
\hline $\begin{array}{l}\text { Ex-situ bismuth film screen-printed } \\
\text { carbon electrode }\end{array}$ & & $9.8-226$ & 2.9 & & \\
\hline Sputtered bismuth screen-printed electrode & & $15.6-226$ & 4.7 & & \\
\hline $\begin{array}{l}\text { Chemically modified electrode based on } \\
\text { dimethylglyoxime-containing carbon paste }\end{array}$ & DPV & 2.9-293.5 & 2.9 & 240 & [35] \\
\hline $\begin{array}{l}\text { Glassy carbon coated with } \\
\text { dimethylglyoxime-containing polymers }\end{array}$ & SWAdCSV & $18-180$ & 18 & 240 & [36] \\
\hline $\begin{array}{l}\text { Chelating agent-modified Nafion-coated } \\
\text { mercury-film electrode }\end{array}$ & SWASV & $0.1-100$ & 0.1 & 300 & [37] \\
\hline Cation exchanger-modified carbon paste electrode & AAdSV & $\begin{array}{c}0.025-6 \\
6-600\end{array}$ & $\begin{array}{l}0.005 \\
0.006\end{array}$ & $720+300^{a}$ & [38] \\
\hline $\begin{array}{c}\text { Carbon paste modified electrode containing } \\
\text { dimethylglyoxime }\end{array}$ & DPV & $0.29-29.3$ & 0.16 & 1500 & [39] \\
\hline $\begin{array}{l}\text { Screen-printed electrodes modified with } \\
\text { dimethylglyoxime in nafion }\end{array}$ & DPV & $60-500$ & 30 & 120 & [40] \\
\hline $\begin{array}{l}\text { Nafion-graphene dimethylglyoxime modified } \\
\text { glassy carbon electrode }\end{array}$ & AdCSV & $2-20$ & 1.5 & 120 & [41] \\
\hline $\begin{array}{l}\text { Dimethylglyoxime modified } \\
\text { screen-printed electrodes }\end{array}$ & DPAdSV & $\begin{array}{l}7.6-200^{\mathrm{b}} \\
23.6-200^{\mathrm{c}}\end{array}$ & $\begin{array}{l}2.3^{\mathrm{b}} \\
7.1^{\mathrm{c}}\end{array}$ & 60 & [42] \\
\hline Hanging mercury drop electrode & SWAdSV & - & 0.003 & $60-180$ & [20] \\
\hline Hanging mercury drop electrode & CSWV & $\begin{array}{c}0.3-6 \\
0.06-6\end{array}$ & $\begin{array}{c}0.1 \\
0.01\end{array}$ & $\begin{array}{c}30 \\
120\end{array}$ & [43] \\
\hline Hanging mercury drop electrode & AdSV & $0.3-3$ & 0.06 & 180 & [44] \\
\hline Hanging mercury drop electrode & SWV & 0-18 & 0.07 & 120 & [45] \\
\hline Screen-printed electrode modified with lead film & SWAdSV & $\begin{array}{c}5.9-35.2 \\
0.6-2.9\end{array}$ & $\begin{array}{l}0.6 \\
0.2\end{array}$ & $\begin{array}{l}60 \\
90\end{array}$ & [46] \\
\hline $\begin{array}{l}\text { In-situ plated lead film on carbon fiber } \\
\text { working microelectrode }\end{array}$ & SWAdSV & $0.1-6$ & 0.05 & 240 & [47] \\
\hline Screen-printed carbon electrode & DPAdSV & $1.7-150$ & 0.5 & 120 & This work \\
\hline
\end{tabular}

${ }^{\text {a }}$ The quantification of nickel takes place after $12 \mathrm{~min}$ of accumulation and $5 \mathrm{~min}$ of deposition. ${ }^{\mathrm{b}}$ Dimethylglyoxime modified screen-printed electrode was prepared from nine additions of $25 \mu \mathrm{L}$ of DMG solution with a rest period of $15 \mathrm{~min}$ between additions. ${ }^{\mathrm{c}}$ Dimethylglyoxime modified screen-printed electrode was prepared from three additions of $75 \mu \mathrm{L}$ of DMG solution with a rest period of 30 min between additions. AAdSV: anodic adsorptive stripping voltammetry, AdSV: adsorptive stripping voltammetry, AdCSV: Adsorptive cathodic stripping voltammetry; CCAdSCP: adsorptive stripping constant current chronopotentiometry; CSWV: cathodic square wave voltammetry, DPAdSV: differential pulse adsorptive stripping voltammetry, DPV: differential pulse voltammetry, SWAdSV: square wave adsorptive stripping voltammetry; SWV: square wave voltammetry.

\subsection{Interference Study}

The potential interference of some frequently occurring metal ions such us Co(II), $\mathrm{Pd}(\mathrm{II}), \mathrm{Pt}(\mathrm{II})$ and $\mathrm{Fe}(\mathrm{III})$ in the determination of $\mathrm{Ni}(\mathrm{II})$ by DPAdSV using a SPCE was assessed. These metal ions could competitively complex with DMG or generate reduction peaks that overlap with or almost entirely suppress the $\mathrm{Ni}(\mathrm{II})$ peak. 
$\mathrm{Ni}(\mathrm{II})$ :metal ion ratios of 4:1, 2:1, 1:1, 1:2, 1:5, 1:10 and 1:50 were investigated, starting with a concentration of $\mathrm{Ni}$ (II) of $10 \mu \mathrm{g} \mathrm{L}^{-1}$ (Figure 3). As an interference criterion, a difference between the peak area of the $\mathrm{Ni}(\mathrm{II})$ without and with the presence of the possible interfering ion higher than $15 \%$ was considered. Stripping voltametric measurements achieved until a 1:5 Ni(II):metal ion ratio indicate that $\mathrm{Co}(\mathrm{II})$ and $\mathrm{Fe}(\mathrm{III})$ do not interfere with the $\mathrm{Ni}(\mathrm{II})$ peak, whereas $\mathrm{Ni}(\mathrm{II})$ :metal ion ratios of 1:10 and 1:50 result in a significant increase of the $\mathrm{Ni}$ (II) peak area with respect to that without $\mathrm{Co}$ (II) or $\mathrm{Fe}(\mathrm{III})$. $\mathrm{Pd}$ (II) also does not display interference until a 1:2 $\mathrm{Ni}(\mathrm{II}): \mathrm{Pd}(\mathrm{II})$ ratio, whereas a considerable increase of the $\mathrm{Ni}(\mathrm{II})$ peak area is observed for ratios of $1: 5$ and 1:10 Ni(II):Pd(II). However, at a $1: 50 \mathrm{Ni}(\mathrm{II}): \mathrm{Pd}(\mathrm{II})$ ratio, the $\mathrm{Ni}(\mathrm{II})$ is practically suppressed. In the case of $\mathrm{Pt}(\mathrm{II})$, at a 1:50 $\mathrm{Ni}(\mathrm{II}): \mathrm{Pt}(\mathrm{II})$ ratio, an increase of the $\mathrm{Ni}(\mathrm{II})$ peak area with respect to that without $\mathrm{Pt}(\mathrm{II})$ of $19 \%$ was achieved, whereas lower $\mathrm{Ni}(\mathrm{II}): \mathrm{Pt}(\mathrm{II})$ ratios did not result in interference.

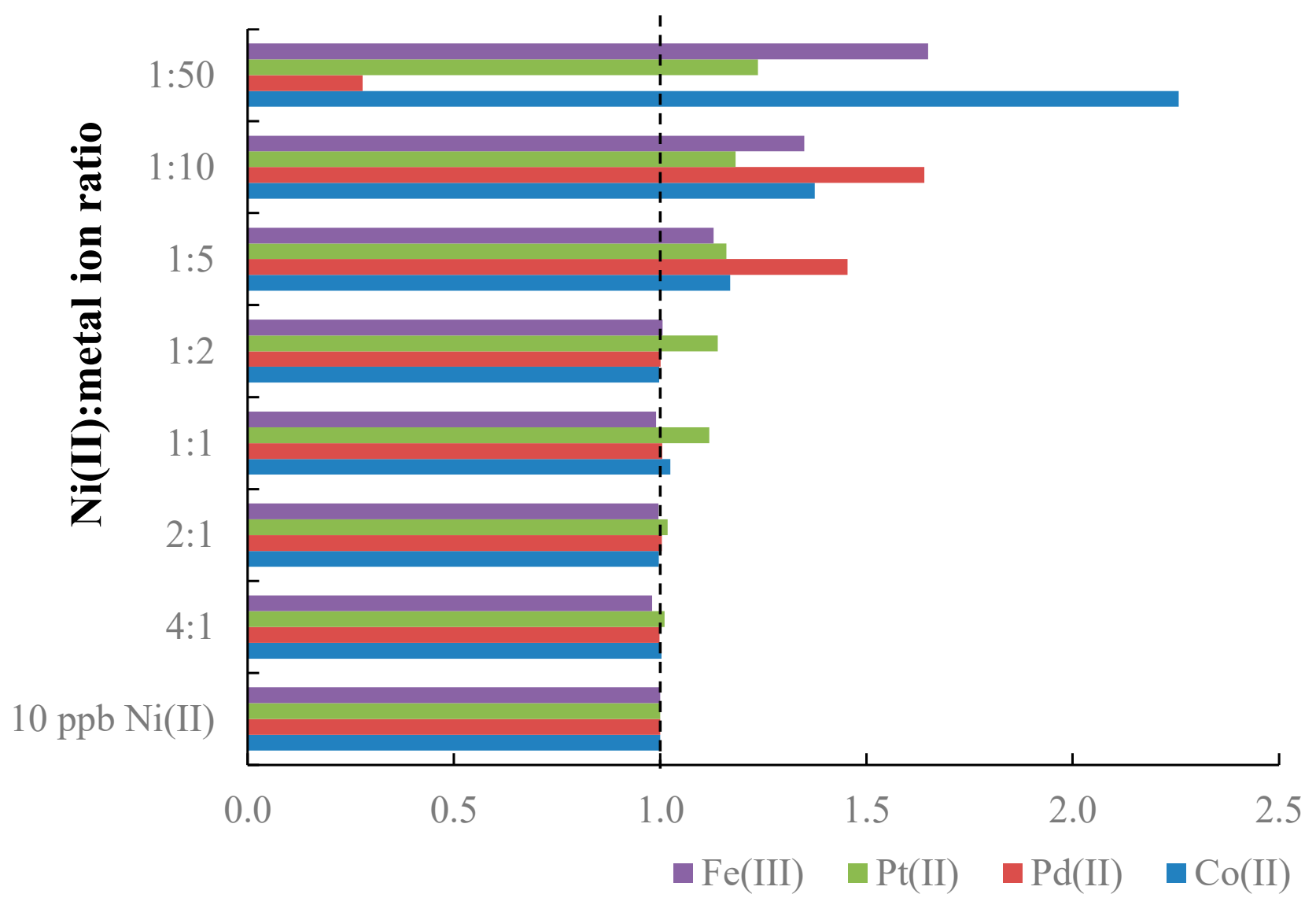

Normalized area (a. u.)

Figure 3. Effect of different $\mathrm{Ni}(\mathrm{II})$ : metal ion ratios on the $\mathrm{Ni}(\mathrm{II})$ peak area. $\mathrm{Co}(\mathrm{II}), \mathrm{Pd}(\mathrm{II}), \mathrm{Pt}(\mathrm{II})$ and Fe(II) were considered as potential interfering metal ions.

Unlike other previous results achieved using bismuth and antimony-based electrodes [27,34], it can be noted that the use of SPCE as sensing unit does not result in overlapping AdSV signals between $\mathrm{Ni}(\mathrm{II})$ and $\mathrm{Co}(\mathrm{II})$, at least until a 1:5 $\mathrm{Ni}(\mathrm{II}): \mathrm{Co}(\mathrm{II})$ ratio, which ensures the successful determination of $\mathrm{Ni}(\mathrm{II})$. This is especially important because both metals ions usually present very close reduction peaks that hinder the determination of one of the metals in the presence of the other.

\subsection{Analysis of a Wastewater Certified Reference Material by Using a SPCE}

The applicability of the DPAdSV method using SPCE was assessed by analyzing Ni(II) in a wastewater certified reference material. The wastewater sample was not subjected 
to any treatment such as digestion, filtration or preconcentration. The determination of $\mathrm{Ni}$ (II)-ions was carried out by means of the standard addition method. Then, DPAdSV measurements were performed at the above optimized conditions, including five additions of $\mathrm{Ni}(\mathrm{II})$. The DPAdSV determination of $\mathrm{Ni}(\mathrm{II})$, in the wastewater sample, was performed in triplicate using a new SPCE unit for each replicate. Figure 4a shows a series of DPAdS voltammograms after standard additions for the determination of $\mathrm{Ni}(\mathrm{II})$ in the wastewater sample. As in the calibration data, a well-shaped $\mathrm{Ni}(\mathrm{II})$ stripping voltametric peak was obtained. A good correlation of the DPAdSV measurement carried out using SPCE was achieved as it is shown in the Ni(II) standard addition calibration plot (Figure 4b). Table 3 reports the $\mathrm{Ni}$ (II) concentration data obtained from the DPAdSV determination of the three replicates of the certified wastewater sample made using the SPCE. An excellent agreement was achieved between all the three replicates, as well as with the certified value of $\mathrm{Ni}$ (II) in the wastewater. Moreover, it should be noted that the certified wastewater solution contains 12 more elements, $\mathrm{Al}, \mathrm{As}, \mathrm{Cd}, \mathrm{Co}, \mathrm{Cr}, \mathrm{Cu}, \mathrm{Fe}, \mathrm{Mn}, \mathrm{P}, \mathrm{Pb}, \mathrm{V}$ and $\mathrm{Zn}$, at concentration ratios Ni:element (calculated in grams) of 1:2, 10:1, 50:1, 17:1, 5:1, 2.5:1, 1:1, 2.5:1, 1:1, 10:1; 10:1 and 1.7:1, respectively, without affecting the determination of $\mathrm{Ni}(\mathrm{II})$ in the sample.

(b)

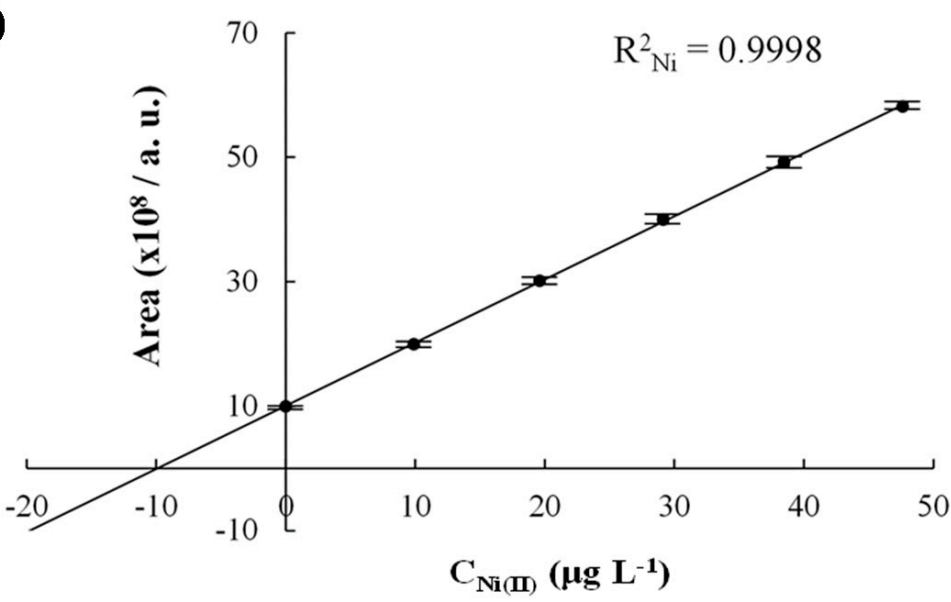

(a)

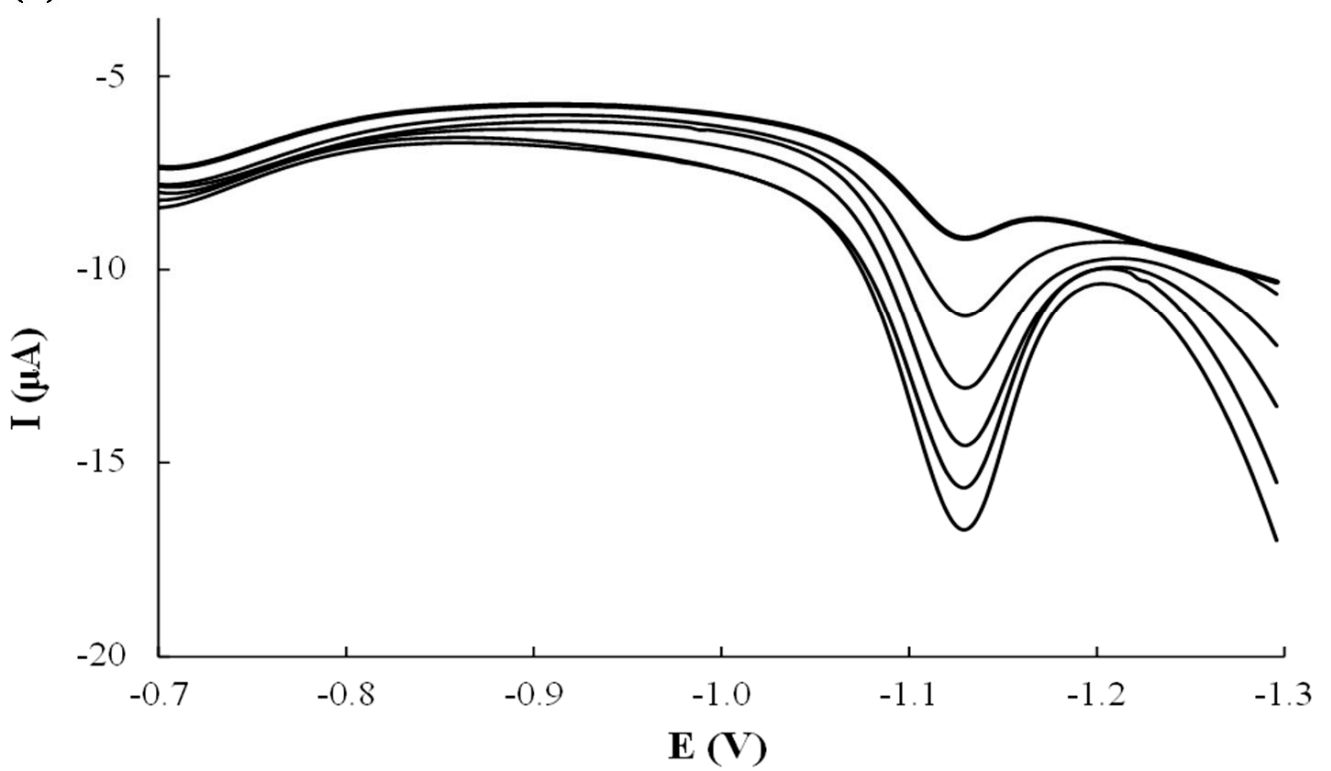

Figure 4. (a) Differential pulse adsorptive stripping voltammograms of $\mathrm{Ni}$ (II) in a wastewater sample using a SPCE in $0.1 \mathrm{~mol} \mathrm{~L}^{-1}$ ammonia/ammonium buffer solution ( $\mathrm{pH} \mathrm{9.2)} \mathrm{and} 5 \times 10^{-5} \mathrm{~mol} \mathrm{~L}^{-1}$ DMG applying a $E_{\mathrm{d}}$ of $-0.7 \mathrm{~V}$ and $a t_{\mathrm{d}}$ of $120 \mathrm{~s}$; (b) Ni(II) standard addition calibration plot. In (b) error bars of the peak areas are shown. 
Table 3. Total concentrations of Ni(II) determined in a wastewater certified reference material (SPSWW2) by AdSV on SPCE by standard addition calibration method at ammonium/ammonia buffer pH 9.2 applying an Ed of $-0.7 \mathrm{~V}$ and a td of $120 \mathrm{~s}$.

\begin{tabular}{cccc}
\hline & c ( $\left.\mathbf{g ~ L ~}^{-1}\right)$ & RSD (\%) & Relative Error (\%) \\
\hline SPCE & 4954.0 & 0.4 & 0.9 \\
Certified metal value & 5000.0 & 0.5 & - \\
\hline
\end{tabular}

Looking at the excellent results obtained in the determination of $\mathrm{Ni}(\mathrm{II})$ in the wastewater sample, we can assert that a disposable and commercial screen-printed carbon electrode can be successfully applied for the AdSV determination of $\mathrm{Ni}(\mathrm{II})$ in the presence of dimethylglyoxime as complexing agent in real water samples at very low concentration levels, even in the presence of other elements at comparable concentrations as Ni(II). Thus, SPCE is an authentic alternative not only to the most classical mercury and bismuth or antimony-based electrodes, but also to the modified electrodes based on DMG for the determination of $\mathrm{Ni}(\mathrm{II})$ in natural samples.

\section{Conclusions}

In this work, two commercial screen-printed electrodes based on carbon (SPCE) and gold (SPAuE) were tested as sensing devices for the determination of Ni(II) by DPAdSV in the presence of DMG as a complexing agent.

The use of SPAuE did not give rise to the typical Ni(II) peak, being ruled out as sensing device for the stripping determination of $\mathrm{Ni}(\mathrm{II})$. However, when a SPCE is used, a well-defined $\mathrm{Ni}$ (II) stripping peak appears that increases proportionally with both $\mathrm{t}_{\mathrm{d}}$ and $\mathrm{Ni}(\mathrm{II})$ concentration. After the optimization of the electrochemical parameters, calibration curves applying an $\mathrm{E}_{\mathrm{d}}$ of $-0.7 \mathrm{~V}$ during a $\mathrm{t}_{\mathrm{d}}$ of $120 \mathrm{~s}$ were conducted. LOD and LOQ at levels of $\mu \mathrm{g} \mathrm{L}^{-1}$ and a linearity of up to $150 \mu \mathrm{g} \mathrm{L}^{-1}$ were achieved. Moreover, as can be inferred from the obtained repeatability values, a SPCE unit can be applied for many measurements without degradation signals. Thus, it can be concluded that all the analytical parameters evaluated were similar or even better than those reported in previous studies for bismuth-based, antimony-based, lead-based or modified electrode-based on DMG.

In addition, SPCE was successfully applied for Ni(II) determination in a wastewater sample as a demonstration of its applicability for natural samples analysis, being able to quantify $\mathrm{Ni}$ (II) concentration with very high trueness and excellent reproducibility, inferred by the relative error $=0.9 \%$ and the $\mathrm{RSD}=0.4 \%$, respectively.

Thus, the good stability, selectivity, reproducibility, and LOD and LOQ at $\mu \mathrm{g} \mathrm{L}^{-1}$ levels added to the inherent strengths of using screen-printed electrodes, i.e., low-cost, disposable character, reproducible units ..., and the lack of modification procedures involved make the SPCE particularly well suited to being implemented in the monitoring of $\mathrm{Ni}$ (II) at low $\mu \mathrm{g} \mathrm{L}^{-1}$ levels in samples of environmental interest.

Supplementary Materials: The following are available online at https://www.mdpi.com/article/ 10.3390/chemosensors9050094/s1, Figure S1: Differential pulse adsorptive stripping voltammograms of $10 \mu \mathrm{g} \mathrm{L-1} \mathrm{Ni(II)} \mathrm{recorded} \mathrm{on} \mathrm{SPCE} \mathrm{in} 0.1 \mathrm{~mol} \mathrm{~L}^{-1}$ ammonia / ammonium buffer solution (pH 9.2) and $5 \times 10^{-5} \mathrm{~mol} \mathrm{~L}^{-1}$ DMG applying a Ed of $-0.7 \mathrm{~V}$ and a td of 30, 60, 90, 120, 180 and $240 \mathrm{~s}$.

Author Contributions: Conceptualization, N.S. and J.M.D.-C.; data curation, V.P. and N.S.; investigation, V.P., N.S. and J.M.D.-C.; methodology, N.S. and J.M.D.-C.; supervision, N.S. and J.M.D.-C.; writing—original draft, N.S.; writing-review and editing, J.M.D.-C. All authors have read and agreed to the published version of the manuscript.

Funding: This research was funded by the Spanish Ministry of Science and Innovation (project PID2019-107102RBC22).

Institutional Review Board Statement: Not applicable.

Informed Consent Statement: Not applicable. 
Acknowledgments: The authors gratefully acknowledge the support (without funding) of the Generalitat of Catalonia, Spain, under the project 2017SGR-311. Víctor Padilla acknowledges the Water Research Institute (IdRA) of the University of Barcelona for the funding required for the acquisition of disposable electrodes and reagents.

Conflicts of Interest: The authors declare no conflict of interest.

\section{References}

1. Wang, J. Stripping Analysis: Principles, Instrumentation and Applications; VCH: Deerfield Beach, FL, USA, 1985.

2. Barek, J.; Fogg, A.G.; Muck, A.; Zima, J. Polarography and voltammetry at mercury electrodes. Crit. Rev. Anal. Chem. 2001, 31, 291-309. [CrossRef]

3. Gumpu, M.B.; Sethuraman, S.; Krishnan, U.M.; Rayappan, J.B.B. A review on detection of heavy metal ions in water-an electrochemical approach. Sens. Actuators B 2015, 213, 515-533. [CrossRef]

4. Bansod, B.; Kumar, T.; Thakur, R.; Rana, S.; Singh, I. A review on various electrochemical techniques for heavy metal ions detection with different sensing platforms. Biosens. Bioelectron. 2017, 94, 443-455. [CrossRef] [PubMed]

5. Ariño, C.; Serrano, N.; Díaz-Cruz, J.M.; Esteban, M. Voltammetric determination of metal ions beyond mercury electrodes. A review. Anal. Chim. Acta 2017, 990, 11-53. [CrossRef] [PubMed]

6. Metters, J.P.; Kadara, R.O.; Banks, C.E. New directions in screen printed electroanalytical sensors: An overview of recent developments. Analyst 2011, 136, 1067-1076. [CrossRef] [PubMed]

7. Barton, J.; González García, M.B.; Hernández Santos, D.; Fanjul-Bolado, P.; Ribotti, A.; McCaul, M.; Diamond, D.; Magni, P. Screen-printed electrodes for environmental monitoring of heavy metal ions: A review. Microchim. Acta 2016, 183, 503-517. [CrossRef]

8. Liu, X.; Yao, Y.; Ying, Y.; Ping, J. Recent advances in nanomaterial-enabled screen-printed electrochemical sensors for heavy metal detection. Trends Anal. Chem. 2019, 115, 187-202. [CrossRef]

9. Duffus, J.H. “Heavy metals"-A meaningless term? Pure Appl. Chem. 2002, 74, 793-807. [CrossRef]

10. Tchounwou, P.B.; Yedjou, C.G.; Patlolla, A.K.; Sutton, D.J. Heavy Metal Toxicity and the Environment. In Molecular, Clinical and Environmental Toxicology; Luch, A., Ed.; Springer: Basel, Switzerland, 2012; Volume 3, pp. 133-164.

11. Lambert, M.; Leven, B.A.; Green, R.M. New methods of cleaning up heavy metal in soils and water. In Environmental Science and Technology Briefs for Citizens; Kansas State University: Manhattan, KS, USA, 2000.

12. Ansari, M.I.; Malik, A. Seasonal variation of different microorganisms with nickel and cadmium in the industrial wastewater and agricultural soils. Environ. Monit. Assess. 2010, 167, 151-163. [CrossRef] [PubMed]

13. Nieminen, T.M.; Ukonmaanaho, L.; Rausch, N.; Shotyk, W. Metal Ions in Life Sciences; John Wiley \& Sons, Ltd.: New York, NY, USA, 2007; Volume 2, pp. 1-30.

14. Das, K.K.; Reddy, R.C.; Bagoji, I.B.; Das, S.; Bagali, S.; Mullur, L.; Khodnapur, J.P.; Biradar, M.S. Primary concept of nickel toxicity-An overview. J. Basic Clin. Physiol. Pharmacol. 2019, 30, 141-152. [CrossRef]

15. Agency for Toxic Substances and Disease Registry (ATSDR). Toxicological Profile for Nickel; Department of Health and Human Services, Public Health Service: Atlanta, GA, USA, 2005.

16. Das, K.K.; Buchner, V. Effect of nickel exposure on peripheral tissues: Role of oxidative stress in toxicity and possible protection by ascorbic acid. Rev. Environ. Health 2007, 22, 133-149. [CrossRef]

17. Das, K.K.; Das, S.N.; Dhundasi, S.A. Nickel: Molecular diversity, application, essentiality and toxicity in human health. In Biometals: Molecular Structures, Binding Properties and Applications; Blanc, G., Moreau, D., Eds.; Nova Science Publishers: New York, NY, USA, 2010; pp. 33-58.

18. IARC (International Agency for Research on Cancer). IARC Monograph on the Evaluation of Carcinogenic Risks to Humans; IARC: Lyon, France, 1990; Volume 49, pp. 318-411.

19. Pihlar, B.; Valenta, P.; Nürnberg, H.W. Electrochemical reduction of Ni(II) on the hanging mercury drop electrode in the presence of dimethylglyoxime. J. Electroanal. Chem. Interf. Electrochem. 1986, 214, 157-177. [CrossRef]

20. Zhang, H.; Wollast, R.; Vire, J.C.; Patriarche, G.J. Simultaneous determination of cobalt and nickel in sea water by adsorptive cathodic stripping square-wave voltammetry. Analyst 1989, 114, 1597-1602. [CrossRef]

21. Serrano, N.; Alberich, A.; Díaz-Cruz, J.M.; Ariño, C.; Esteban, M. Coating methods, modifiers and applications of bismuth screen-printed electrodes. Trends Anal. Chem. 2013, 46, 15-29. [CrossRef]

22. Serrano, N.; Díaz-Cruz, J.M.; Ariño, C.; Esteban, M. Antimony-based electrodes for analytical determinations. Trends Anal. Chem. 2016, 77, 203-213. [CrossRef]

23. Wang, J.; Lu, J. Bismuth film electrodes for adsorptive stripping voltammetry of trace nickel. Electrochem. Commun. 2000, 2, 390-393. [CrossRef]

24. Hutton, E.A.; Hocevar, S.B.; Ogorevc, B.; Smyth, M.R. Bismuth film electrode for simultaneous adsorptive stripping analysis of trace cobalt and nickel using constant current chronopotentiometric and voltammetric protocol. Electrochem. Commun. 2003, 5, 765-769. [CrossRef]

25. Morfobos, M.; Economou, A.; Voulgaropoulos, A. Simultaneous determination of nickel(II) and cobalt(II) by square wave adsorptive stripping voltammetry on a rotating-disc bismuth-film electrode. Anal. Chim. Acta 2004, 519, 57-64. [CrossRef]

26. Hutton, E.A.; Hocevar, S.B.; Ogorevc, B. Ex situ preparation of bismuth film microelectrode for use in electrochemical stripping microanalysis. Anal. Chim. Acta 2005, 537, 285-292. [CrossRef] 
27. Kokkinos, C.; Economou, A.; Raptis, I.; Speliotis, T. Disposable mercury-free cell-on-a-chip devices with integrated microfabricated electrodes for the determination of trace nickel(II) by adsorptive stripping voltammetry. Anal. Chim. Acta 2008, 622, 111-118. [CrossRef]

28. Kokkinos, C.; Economou, A.; Raptis, I.; Speliotis, T. Novel disposable microfabricated antimony-film electrodes for adsorptive stripping analysis of trace Ni(II). Electrochem. Commun. 2009, 11, 250-253. [CrossRef]

29. Korolczuk, M.; Rutyna, I.; Tyszczuk, K. Adsorptive stripping voltammetry of nickel at an in situ plated bismuth film electrode. Electroanalysis 2010, 22, 1494-1498. [CrossRef]

30. Sopha, H.; Jovanovski, V.; Hocevar, S.B.; Ogorevc, B. In-situ plated antimony film electrode for adsorptive cathodic stripping voltammetric measurement of trace nickel. Electrochem. Commun. 2012, 20, 23-25. [CrossRef]

31. Alves, G.M.S.; Magalhães, J.M.C.S.; Soares, H.M.V.M. Simultaneous determination of nickel and cobalt using a solid bismuth vibrating electrode by adsorptive cathodic stripping voltammetry. Electroanalysis 2013, 25, 1247-1255. [CrossRef]

32. Dal Borgo, S.; Sopha, H.; Smarzewska, S.; Hočevar, S.B.; Švancara, I.; Metelka, R. Macroporous bismuth film screen-printed carbon electrode for simultaneous determination of Ni(II) and Co(II). Electroanalysis 2015, 27, 209-216. [CrossRef]

33. Bas, B.; Wegiel, K.; Jedlinska, K. The renewable bismuth bulk annular band working electrode: Fabrication and application in the adsorptive stripping voltammetric determination of nickel(II) and cobalt(II). Anal. Chim. Acta 2015, 881, 44-53. [CrossRef]

34. Barceló, C.; Serrano, N.; Ariño, C.; Díaz-Cruz, J.M.; Esteban, M. Ex-situ antimony screen-printed carbon electrode for voltammetric determination of $\mathrm{Ni}(\mathrm{II})$ - Ions in wastewater. Electroanalysis 2016, 28, 640-644. [CrossRef]

35. Baldwin, R.P.; Christensen, J.K.; Kryger, L. Voltammetric determination of traces of nickel(II) at a chemically modified electrode based on dimethylglyoxime-containing carbon paste. Anal. Chem. 1986, 58, 1790-1798. [CrossRef]

36. Bing, C. Chemical accumulation and voltammetric determination of traces of nickel(II) at glassy carbon electrodes modified with dimethylglyoxime containing polymer coatings. Talanta 1999, 49, 651-659. [CrossRef]

37. Tien, H. The application of chelating agent incorporated polymer modified electrodes in the detection of trace metals. J. Chin. Chem. Soc. 1998, 45, 39-46. [CrossRef]

38. González, P.; Cortínez, V.A.; Fontán, C.A. Determination of nickel by anodic adsorptive stripping voltammetry with a cation exchanger-modified carbon paste electrode. Talanta 2002, 58, 679-690. [CrossRef]

39. Tartarotti, F.O.; De Oliveira, M.F.; Balbo, V.R.; Stradiotto, N.R. Determination of nickel in fuel ethanol using a carbon paste modified electrode containing dimethylglyoxime. Microchim. Acta 2006, 155, 397-401. [CrossRef]

40. Ferancová, A.; Hattuniemi, M.K.; Sesay, A.M.; Räty, J.P.; Virtanen, V.T. Rapid and direct electrochemical determination of Ni(II) in industrial discharge water. J. Hazard. Mater. 2016, 306, 50-57. [CrossRef] [PubMed]

41. Pokpas, K.; Jahed, N.; Baker, P.G.; Iwuoha, E.I. Complexation-based detection of nickel(II) at a graphene-chelate probe in the presence of cobalt and zinc by adsorptive stripping voltammetry. Sensors 2017, 17, 1711. [CrossRef] [PubMed]

42. Rosal, M.; Cetó, X.; Serrano, N.; Ariño, C.; Esteban, M.; Díaz-Cruz, J.M. Dimethylglyoxime modified screen-printed electrodes for nickel determination. J. Electroanal. Chem. 2019, 839, 83-89. [CrossRef]

43. Korolczuk, M. Voltammetric method for direct determination of nickel in natural waters in the presence of surfactants. Talanta 2000, 53, 679-686. [CrossRef]

44. Mahajan, R.K.; Dhawan, P. Adsorptive stripping voltammetric determination of nickel(II) using N-2-pyridyl-benzamidine as a complexing reagent. Indian J. Chem. 2002, 41, 981-984.

45. Korolczuk, M. Voltammetric determination of nickel in the flow system in the presence of an extremely large excess of cobalt and zinc. Electroanalysis 2000, 12, 1502-1504. [CrossRef]

46. Bobrowski, A.; Królicka, A.; Maczuga, M.; Zarębski, J. A novel screen-printed electrode modified with lead film for adsorptive stripping voltammetric determination of cobalt and nickel. Sens. Actuators B 2014, 191, 291-297. [CrossRef]

47. Ochab, M.; Geca, I.; Korolczuk, M. The new micro-set for adsorptive stripping voltammetric simultaneous determination of nickel and cobalt traces in aqueous media. Electroanalysis 2019, 31, 1769-1774. [CrossRef] 